\title{
Cultura política e política cultural
}

\author{
MARIENA CHAUI'
}

$\mathrm{E}$

NTRE 1989 e 1992, na cidade de São Paulo, o Partido dos Trabalhadores (PT) esteve no governo municipal que, pela primeira vez nos cinco séculos da história do país e' da cidade, viu no poder um partido de esquerda de origem fortemente popular e que, nascido de movimentos sociais e sindicais, tem sido responsável por grande parte da democratização do Brasil.

\section{O desafio}

O desafio imposto pelas condiçóes históricas (sociais e econômicas) e pelo imaginário político (fortemente conservador, na cidadé de São Paulo), exigia que em cada campo de atividade governamental fossem realizados três trabalhos simultâneos: a mudança na mentalidade dos servidores públicos municipais, a definição de prioridades voltadas para as carências e demandas das classes populares e a invenção de uma nova cultura política.

Do ponto de vista administrativo, tratava-se de fazer com que os servidores públicos se considerassem cidadãos a serviço de outros cidadãos, em lugar de funcionários do aparelho estatal. Em outras palavras, tratava-se de quebrar o poderio burocrático, fundado na hierarquia, no segredo do cargo e na rotina, isto é, em práticas antidemocráticas, uma vez que a democracia funda-se na igualdade (contra a hierarquia), no direito à informação (contra o segredo) e na invenção de novos direitos segundo novas circunstâncias (contra a rotina).

Do ponto de vista das prioridades, tratava-se de definir políticas públicas para as áreas de saúde, moradia, educação, transporte, alimentação, cultura e direitos das minorias, numa cidade que recebe anualmente cerca de 150 mil migrantes pobres e, além de sofrer os efeitos da recessão reinante no país, está passando por uma mudança profunda, pois começa a deixar de ser um centro industrial para tornar-se um centro de serviços.

Do ponto de vista da cultura política, tratava-se de estimular formas de auto-organização da sociedade e sobretudo das camadas populares, criando o sentimento e a prática da cidadania participativa. 
Foi sob o imperativo dessas três exigências que a Secretaria Municipal de Cultura desenvolveu um projeto cuja diretriz fundamental foi a Cidadania Cultural. Pode parecer estranho (dado o modo como correntemente se entende a cultura como lazer e entretenimento) que a natureza política do trabalho se exprimisse de maneira tão explícita e direta num projeto cultural. Para que a estranheza não permaneça, é preciso considerar as condiçōes (e pré-condições) para propor uma política cultural no Brasil e, particularmente, em São Paulo, a mais capitalista das cidades brasileiras, na qual a logica do mercado funciona plenamente.

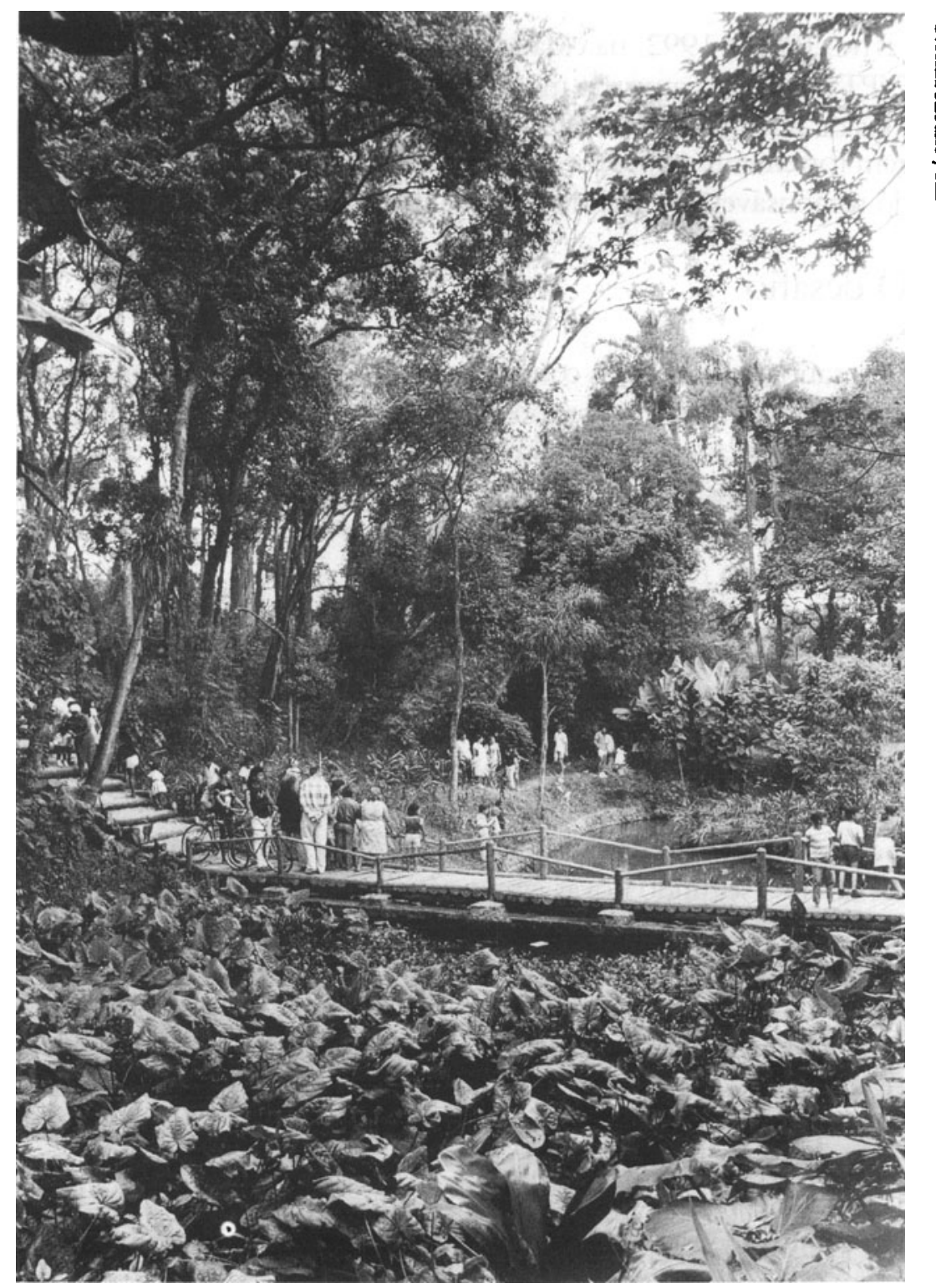

O Parque Ecológico Chico Mendes, localizado no bairro de São Miguel Paulista, em São Paulo, tem 66 mil metros quadrados de área verde e foi inaugurado em 4 de junbo de 1989 pela então prefeita Luiza Erundina. 
O desafio apresentou-se como enfrentamento de três poderosos mecanismos que determinam as operaçóes, funcionamentos e reproduções do imaginário social e político no Brasil: o mecanismo mitológico, o ideológico e o político.

\section{A máquina mitológica}

O grande mito que sustenta a imaginação social brasileira é o da não-violência. Nossa auto-imagem é a de um povo ordeiro e pacífico, alegre e cordial, mestiço e incapaz de discriminações étnicas, religiosas ou sociais, acolhedor para os estrangeiros, generoso para com os carentes, orgulhoso das diferenças regionais e destinado a um grande futuro.

Muitos indagarão como o mito da não-violência brasileira pode persistir sob o impacto da violência real, cotidiana, conhecida de todos e que, nos últimos tempos, é também ampliada por sua divulgação e difusão pelos meios de comunicação de massa. Ora, é justamente no modo de interpretação da violência que o mito encontra meios para conservar-se.

De fato, o primeiro mecanismo empregado para interpretar a violência é o da exclusão: afirma-se que a nação brasileira é não-violenta e que, se houver violência, esta é praticada por gente que não faz parte da nação (mesmo que tenha nascido e viva no Brasil). O mecanismo da exclusão produz a diferença entre um nós-brasileiros-não violentos e um eles-não-brasileiros-piolentos. Eles não fazem parte do nós.

O segundo mecanismo é o da distinção: distingue-se o essencial e o acidental, isto é, por essência, os brasileiros não são violentos e, portanto, a violência é acidental, um acontecimento efêmero, passageiro, uma epidemia ou um surto localizado na superfície de um tempo e de um espaço definidos, superável e que deixa intacta nossa essência não-violenta.

O terceiro mecanismo é de tipo jurídico: a violência fica circunscrita ao campo da delinqüência e da criminalidade, o crime sendo definido como ataque à propriedade privada (furto, roubo e latrocínio, ou seja, roubo seguido de assassinato). Esse mecanismo permite, por um lado, determinar quem são os agentes violentos (de modo geral, os pobres) e legitimar a ação (esta sim, violenta) da polícia contra a população pobre, os negros, as crianças de rua e os favelados. A ação policial pode ser, às vezes, considerada violenta, recebendo o nome de chacina ou massacre quando, de uma só vez e sem motivo, o número de assassinados é muito elevado. No restante das vezes, porém, o assassinato policial é considerado normal e natural, uma vez que se trata de proteger o nós contra o eles.

O quarto mecanismo é de tiposociológico: atribui-se aepidemia de violência 
a um momento definido do tempo, aquele no qual se realiza a transição para a modernidade das populações que migraram do campo para a cidade e das regióes mais pobres (norte e nordeste) para as mais ricas (sul e sudeste). A migraçáo causaria o fenômeno temporário da anomia, no qual a perda das formas antigas de sociabilidade ainda não foram substituídas por novas, fazendo com que os migrantes pobres tendam a praticar atos isolados de violência que desaparecerão quando estiver completada a transição. Aqui, não só a violência é atribuída aos pobres e desadaptados, como ainda é consagrada como algo temporário ou episódico.

Finalmente, o último mecanismo é o da inversão do real, graças à produção de máscaras que permitem dissimular comportamentos, idéias e valores violentos como se fossem não-violentos. Assim, por exemplo, o machismo é colocado como proteção natural à natural fragilidade feminina; o paternalismo branco é visto como proteção para auxiliar a natural inferioridade dos negros; a repressão contra os homossexuais é considerada proteção natural aos valores sagrados da família; a destruição do meio ambiente é orgulhosamente vista como sinal de progresso e civilização etc.

Em resumo, a violência não é percebida como toda prática e toda idéia que reduza um sujeito à condição de coisa, que viole interior e exteriormente o ser de alguém, que perpetue relaçóes sociais de profunda desigualdade econômica, social e cultural. $O$ mito da não-violência permanece porque admite-se a existência empirica da violência, mas fabricam-se explicaçôes para denegá-la no instante mesmo em que é admitida. Mais do que isso, a sociedade não percebe que as próprias explicaçôes oferecidas são violentas. Dessa maneira, a violência que estrutura e organiza as relaçóes sociais brasileiras, por não ser percebida, é naturalizada e essa naturalizaçấo conserva a mitologia da não-violência.

\section{A máquina ideológica}

A mitologia da não-violência é o solo sobre o qual se ergue a ideologia, sob a forma das relaçóes sociais.

Afirma-se que no Brasil, infelizmente, atravessamos periodicamente fases de autoritarismo, visto como um acontecimento referido ao regime político e ao modo de funcionamento do Estado ditatorial. Dessa maneira, dissimula-se o fundamental, isto é, que o autoritarismo não é simplesmente a forma do governo, mas a estrutura da própria sociedade brasileira. Esta.é visceralmente autoritária.

Conservando as marcas da sociedade colonial escravocrata, a sociedade brasileira é fortemente hierarquizada: nela, as relaçôes sociais e intersubjetivas são 
sempre realizadas como relação entre um superior, que manda, e um inferior, que obedece. As diferenças e assimetrias são sempre transformadas em desigualdades que reforçam a relação mando-obediência. O outro jamais é reconhecido como sujeito nem como sujeito de direitos, jamais é reconhecido como subjetividade nem como alteridade. As relações, entre os que se julgam iguais, são de cumplicidade; e, entre os que são vistos como desiguais, o relacionamento toma a forma do favor, do clientelismo, da tutela ou da cooptação, e, quando a desigualdade é muito marcada, assume a forma da opressão. Em suma: micropoderes capitalizam o autoritarismo em toda a sociedade: na família, na escola, nas relaçóes amorosas, no trabalho, na mass midia, no comportamento social nas ruas, no tratamento dado aos cidadãos pela burocracia estatal, no desprezo do mercado pelos direitos do consumidor, na naturalidade da violência policial etc.

Podemos resumir, simplificadamente, os principais traços de nosso autoritarismo social considerando que a sociedade brasileira se caracteriza pelos seguintes aspectos:

- incapacidade para operar o princípio liberal da igualdade formal e para lutar pelo princípio socialista da igualdade real: as diferenças são postas como desigualdades e, estas, como inferioridade (no caso das mulheres, dos trabalhadores, dos negros, índios, migrantes, idosos) ou como monstruosidade (no case dos homossexuais);

- incapacidade para operar com o princípio liberal da igualdade jurídica e para lutar contra formas de opressão social e econômica is para os grandes, a lei é privilégio; para as camadas populares, repressão. A lei não consegue figurar o pólo público do poder e da regulaçáo dos conflitos, nunca definindo direitos e deveres dos cidadãos. Por este motivo, as leis aparecem como inócuas, inúteis ou incompreensíveis, feitas para serem transgredidas e não para serem transformadas. O poder judiciário surge como distante, secreto, representante dos privilégios das oligarquias e náo dos direitos da generalidade social;

- indistinção entre o público e o privado: não apenas os governantes e parlamentares praticam a corrupçáo sobre os fundos públicos, mas não há a percepçáo social de uma esfera pública das opinióes, da sociabilidade coletiva, da rua como espaço comum, assim como não há a percepção dos direitos à privacidade e à intimidade. Do ponto de vista dos direitos sociais, há unt encolhimento público; do ponto de vista dos interesses econômicos, um alargamento do privado, tornando a sociedade presa fácil do neoliberalismo e por ele fascinada;

- incapacidade para trabalhar conflitos e contradiçóes sociais, econômicas e políticas. Conflitos e contradiçóes são sempre considerados perigo, crise, desordem e a eles se oferece uma única resposta: a repressão policial e militar; 
- incapacidade para criar a esfera pública da opinião como expressão dos interesses e dos direitos de grupos e classes sociais diferenciados e/ou antagônicos. A mass midia monopoliza a informação e o consenso é confundido com a unanimidade, de sorte que a discordância é posta como ignorância, atraso ou ignorância;

- incapacidade para tolerar e fortalecer movimentos populares e sociais: a sociedade civil auto-organizada é vista como perigosa para o Estado e para o funcionamento selvagem do mercado;

- a naturalização das desigualdades econômicas e sociais (o salário mínimo oscila entre 20 e 60 dólares por mês, sendo considerado natural que os trabalhadores tenham dificuldades até mesmo para reproduzir-se como força de trabalho), do mesmo modo que há naturalização das diferenças étnicas como desigualdades raciais entre superiores e inferiores, das diferenças religiosas e de gênero, bem como naturalização de todas as formas visíveis e invisíveis de violência;

- fascínio pelos signos de prestígio e de poder: uso de títulos honoríficos sem qualquer relação com a possível pertinência de sua atribuição, o caso mais corrente sendo o uso de doutor quando, na relação social, o outro se sente ou é visto como superior, doutor é o substituto imaginário para os antigos títulos de nobreza do período colonial e da monarquia; manutenção de criadagem doméstica, cujo número indica aumento de prestígio, de status etc.

O autoritarismo está de tal modo interiorizado nos corações e nas mentes que alguém pode usar a frase "um negro muito bom porque tem a alma branca" e não ser considerado racista. Pode referir-se aos serviçais domésticos nos termos "uma criada muito boa porque conhece seu lugar" e considerar-se isento de preconceito de classe. Pode referir-se a um assalariado como "um empregado de toda confiança porque nunca rouba coisa alguma" e considerar que não existe luta de classes e que dela não participa. Pode dizer "uma mulher perfeita, pois não trocou o lar pela indignidade de trabalhar fora" e não ser considerado machista.

A desigualdade salarial entre homens e mulheres, entre brancos e negros, a exploração do trabalho infantil e dos idosos são consideradas normais. A existência dos sem-terra, dos sem-teto, dos desempregados é atribuída à ignorância, à preguiça e à incompetência dos miserápeis. A existência de crianças de rua é vista como "tendência natural dos pobres à criminalidade". Os acidentes de trabalho são imputados à incompetência e à ignorância dos trabalhadores. As mulheres que trabalham (se não forem professoras ou assistentes sociais) são consideradas prostitutas em potencial e as prostitutas, degeneradas, perversas e criminosas, embora, infelizmente, indispensáveis para conservar a santidade da família. 
O Brasil ocupa o segundo lugar mundial nos índices de concentração da renda e de má distribuição da riqueza, mas ocupa o oitavo lugar em termos do Produto Interno Bruto. Essa desigualdade - 2\% possuem $92 \%$ da renda nacional, enquanto $98 \%$ possuem $8 \%$ dessa renda - não é percebida como socialmente inaceitável, mas natural e normal. Conseqüentemente, a sociedade brasileira é oligárquica e está polarizada entre a carência absoluta das camadas populares e $o$ privilégio absoluto das camadas dominantes e dirigentes.

A ideologia autoritária, que naturaliza as desigualdades e exclusões sócioeconômicas, vem exprimir-se no modo de funcionamento da política.

\section{A máquina política}

Pode-se imaginar a configuração do campo político e de suas práticas quando seu solo é a mitologia da não-violência e a ideologia autoritária.

Os partidos políticos sãoclubs privés das oligarquias regionais, arrebanhando a classe média em torno do imaginário autoritário (a ordem) e mantendo com os eleitores quatro tipos principais de relaçốes: a de cooptação, a de favor e clientela, a de tutela e a da promessa salvacionista ou messiânica. Do lado da classe dominante, a política é praticada numa perspectiva naturalista-teocrática, isto é, os dirigentes são detentores do poder por direito natural e por escolha divina. Do lado das camadas populares, o imaginário político é messiânico-milenarista, correspondendo à auto-imagem dos dirigentes. Como consequiência, a política não consegue configurar-se como campo social de lutas, mas tende a passar para o plano da representação teológica, oscilando entre a sacralização e adoração do bom-governante e a satanização e execração do mau-governante.

O Estado é percebido apenas sob a face do poder executivo, os poderes legislativo e judiciário ficando reduzidos ao sentimento de que o primeiro é corrupto e o segundo, injusto. Nenhuma das funçōes estatais, portanto, é conhecida. A identificação entre o Estado e o executivo, a ausência de um legislativo confiável e o medo do judiciário, somados à ideologia do autoritarismo social e ao imaginário teológico-político levam ao desejo permanente de um Estado forte para a salvação nacional. Por seu turno, o Estado percebe a sociedade civil como inimiga e perigosa, bloqueando as iniciativas dos movimentos sociais, sindicais e populares.

Nestas condiçóes, é possível compreender a dificuldade gigantesca para a instituiçăo da democracia. Dentre as dificuldades, destacamos, aqui, as que nos parecem mais fortes:

- a estrutura oligárquica dos partidos políticos e seu funcionamento, impedindo a idéia e a prática da representação e da participação; 
- a estrutura fortemente burocratizada do Estado e, portanto, como observamos no início, a existência de um poder burocrático cuja natureza é essencialmente antidemocrática;

- a estrutura da sociedade, fundada na polarização extrema entre a carência e o privilégio. Uma carência, por definição, é sempre particular e específica, não conseguindo se generalizar num interesse nem, muito menos, se universalizar num direito. Um privilégio, por definição, não pode se generalizar num interesse comum nem se universalizar num direito, sob a pena de desfazer-se como privilégio. Ora, a democracia é a criação, reconhecimento e garantia de direitos, de sorte que a estrutura da sociedade brasileira impede sua emergência.

Acrescentamos a essas três dificuldades, a presença crescente do neoliberalismo com suas duas marcas principais: do lado da economia, uma acumulação do capital que não necessita incorporar mais pessoas ao mercado de trabalho e de consumo, operando com o desemprego estrutural; do lado da política, a privatização do público, isto é, o abandono das políticas sociais por parte do Estado. No caso do Brasil, o neoliberalismo significa levar ao extremo a polarização carência-privilégio, a exclusão sócio-política das camadas populares, a desorganização da sociedade civil como massa dos desempregados, a natureza oligárquica e tcológica da política, o autoritarismo social e o bloqueio à democracia. Um dos efeitos mais terríveis do neoliberalismo brasileiro tem sido o esfacelamento dos movimentos sociais e populares que foram os grandes sujeitos históricos e políticos dos anos 70 e 80.

\section{O mito fundador}

Os traços que esboçamos acima são determinados na estrutura econômica e social do Brasil. Todavia, para além (ou, talvez, aquém) dessas condiçóes materiais, dando-lhes sustentação imaginária, encontra-se algo próximo e remoto, permanentemente reatualizado sob a variação contínua da mitologia da não-violência e da ideologia autoritária. Trata-se do mito fundador.

Fundador, no sentido da antiga idéia romana da fundatio, ou seja, da construção da origem e de sua ligação perpétua com o presente, dando-lhe forma e sentido. Mito em duas acepções: na antropológica (solução imaginária de tensões e conflitos que não podem ser resolvidos no real) e na psicanalítica (construção imaginária que recalca os conflitos para poder repeti-los incessantemente sob a forma de sintomas).

De Cristovão Colombo, Vespúcio, Pero Vaz de Caminha ao Padre Vieira (no século XVII), dos Inconfidentes Mineiros (século XVIII) às revoltas populares do século XIX (Canudos, Pedra Bonita), do Estado Novo (ditadura fascista 
dos anos 30 e 40) à Nova República (1985) e Fernando Collor de Mello (1990), o mito fundador não cessou de repor-se em vestes novas.

Quando lemos os diários de viagem e as cartas de Colombo ou Vaz de Caminha ou as obras políticas do Padre Vieira, um traço lhes é comum: a América, primeiro, e o Brasil, depois, não são propriamente descobertos, mas encontrados, Já estavam lá e já estavam acabados na mente de navegantes e evangelizadores. De que modo já estapa lá? Como livro ou texto? Os textos antigos de Virgílio e Plínio, o Jovem, os do cardeal medieval Pierre d'Ailly, as lendas e oráculos celtas, as profecias de Isaías e Daniel e as obras profético-milenaristas do abade Joaquim de Fiori já haviam descrito, com profusão de detalhes o Paraíso Terrestre, situado, pelo livro da Gênese, no Oriente. Essa literatura, constituída por um conjunto de lugares-comuns clássicos e bíblicos, produz a imagem do Jardim do Eden: cortado por quatro rios que atravessam a Terra, pelos quais correm leite e mel e cujos leitos estão recobertos de ouro, prata, pérolas, safiras e rubis; cercado por altíssimas montanhas, cobertas de esmeraldas e turmalinas; vegetação luxuriante, flora e fauna exuberantes e exóticas, mares serenos, céus de puro anil e com estrelas desconhecidas, temperatura sempre amena (nem muito quente, nem muito frio, repete a literatura), habitado por gente bela, indômita $\mathrm{e}$ inocente como no dia da criação; primavera eterna, renovação cósmica perpétua. É assim que navegantes e missionários descrevem a América e o Brasil. Não podem vê-los, mas já os conhecem: o olhar busca apenas comprovação empírica para o já sabido, porque escrito. Não descrevem: realizam exegeses.

Se navegantes e missionários insistem em que estão no Oriente e no mundo novo é porque essas duas marcas desenham o Paraíso Terrestre e confirmam as profecias bíblicas. Além disso, Joaquim de Fiori profetizara que da Espanha sairia o Imperador dos Últimos Dias, que venceria o Anti-Cristo (os mouros) e prepararia o caminho para a Segunda Vinda de Cristo, dando início ao Reino de Mil Anos de felicidade e abundância, antes da ressurreição dos mortos e do Juízo Final, de modo que Colombo escreverá aos reis assegurando-lhes que "foram cumpridas as profecias de Daniel e Isaías, tal como profetizara o abade Joaquim". $\mathrm{Na}$ História do Futuro, o mesmo topos é repetido por Vieira, mas, agora, o Imperador dos Últimos Dias é o Encoberto e o Encantado do trovador Bandarra, isto é, El Rei Don Sebastiāo, com quem começará o Quinto Império do mundo, a Jerusalém Celeste. O signo profético decisivo para Vieira é o norte do Brasil: o jesuíta o decifra a partir das profecias de Isaías, lidas como descrição minuciosa e detalhada do Brasil.

As raízes de nosso mito fundador encontram-se fincadas nos primeiros textos dos viajantes e evangelizadores, dando-lhe conteúdo profético-milenarista. Ora, a literatura antiga e medieval que serve de base aos descobridores refere-se ao Paraíso Terrestre como jardim e, dessa maneira, os novos textos colocam a 
nova terra sob o signo da Natureza e não sob o da História e da Cultura. Quando o tempo aparece, surge sob o signo da história providencial do plano divino e do milênio, portanto, como teofania, epifania e história sagrada. Esta, faz do tempo instrumento da eternidade e, portanto, deixa-nos táo fora da história quanto a natureza paradisíaca.

Essa matriz mítica é decisiva para a elaboração do imaginário brasileiro e da auto-imagem do Brasil. Antes de mais nada, como todos sabem, "o Brasil é um dom de Deus aos homens", demonstrado pela ausência de violência natural não temos vulcôes, terremotos, maremotos, tufōes nem desertos (há $\mathbf{5 0 0}$ anos isso é repetido) - e pela clemência primaveril da natureza - nosso Hino Nacional refere-se ao país como "florão da América" cujos céus "tem mais estrelas" e cujos "bosques tem mais flores". Nas escolas, as crianças aprendem o significado das quatro cores de nossa bandeira: o verde, nossas luxuriantes florestas; o amarelo, nossas inesgotáveis riquezas minerais; 0 azul, nosso céu de anil onde brilha o símbolo de nossa eleição divina, o Cruzeiro do Sul; o branco, a paz e a ordem (com progresso) de um povo varonil, justo, generoso, cordial, pacífico e ordeiro. Somos o bom-selvagem, por natureza e por divina providência, pois, somos herdeiros da inocência dos nativos do Pará́so (ainda que os tenhamos dizimado num genocídio sistemático).

Estamos, profeticamente, destinados à grandeza do futuro, pois, nascido sob o signo do milênio, "o Brasil é o país do futuro", pelo qual não precisamos lutar porque nos está prometido desde o começo do mundo.

Eis porque violência e autoritarismo não encontram meios para serem percebidos e superados: não existem porque não podem existir. Eis também porque a política se realiza sob o signo da teofania e da teologia política, uma vez que o tempo nacional é epifânico e milenarista. Do lado dos dominantes, a teologia política manifesta-se numa visão populista-teocrática do poder - o governante representa a vontade divina e não os governados que são usados, através do voto, como instrumentos de Deus na escolha dos dirigentes. Do lado dos dominados, a religião torna-se o único meio de acesso ao político que, por isso, é interpretado sob a forma messiânica - sacralizando o poder - ou sob a forma do flagelo satanizando o poder.

\section{Cidadania Cultural}

Esperamos ter oferecido alguns elementos para esclarecer porque, no Brasil, uma política cultural torna-se inseparável da invenção de uma cultura política nova e que assinalem as dificuldades ou o desafio para implantá-la. Como suscitar nos indivíduos, grupos e classes a percepção de que são sujeitos sociais e políti- 
cos? Como tornar evidente que carências, privilégios, exclusões e opressão não são naturais nem impostas pela Providência divina?

No caso específico da política cultural, não é possível deixar na sombra o modo como a tradição oligárquica autoritária opera com a cultura, a partir do Estado, se se quiser inventar uma nova política.

Quatro tem sido as principais modalidades de relação do Estado com a cultura, no Brasil.

- A liberal, que identifica cultura e belas-artes, estas últimas consideradas a partir da diferença clássica entre artes liberais e servis. Na qualidade de artes liberais, as belas-artes são vistas como privilégio de uma elite escolarizada e consumidora de produtos culturais.

- A do Estado autoritário, na qual o Estado se apresenta como produtor oficial de cultura e censor da produção cultural da sociedade civil.

- A populista, que manipula uma abstração genericamente denominada cultura popular, entendida como produção cultural do povo e identificada com o pequeno artesanato e o folclore, isto é, com a versão popular das belas-artes e da indústria cultural.

- A neoliberal, que identifica cultura e evento de massa, consagra todas as manifestações do narcisismo desenvolvidas pela mass midia, e tende a privatizar as instituiçóes públicas de cultura deixando-as sob a responsabilidade de empresários culturais.

Do lado dos produtores e agentes culturais, o modo tradicional de relação com os órgãos públicos de cultura é o clientelismo individual ou das corporaçóes artísticas que encaram o Estado sob a perspectiva do grande balcão de subsídios e patrocínios financeiros.

Face a esse conjunto de práticas, nossa experiência realizou-se na contracorrente, como crítica do estabelecido e proposta de inovação.

Contra a visão liberal, propusemos alagar o conceito de cultura para além do campo das belas-artes, tomando-o no sentido antropológico mais amplo de invenção coletiva de símbolos, valores, idéias e comportamentos, de modo a afirmar que todos os indivíduos e grupos são seres culturais e sujeitos culturais. 
Contra a visão autoritária, negamos que o Estado deva ser produtor de cultura, procurando, para isso, diferenciar entre estadismo cultural (cultura oficial) e dimensão pública da cultura (o Estado estimula a criação cultural da sociedade).

Contra a visão populista, recusamos a reduçáo da cultura à polaridade entre popular e de elite, enfatizando que a diferença na criaçáo cultural passa por outro lugar, qual seja, entre a experimentação inovadora e crítica e a repetição conservadora, pois tanto uma quanto outra podem estar presentes tanto na produçáo dita de elite quanto na chamada popular.

- Contra a visão neoliberal, procuramos enfatizar o caráter público da ação cultural do Estado, a abertura de campos de atividade não submetidos ao poderio dos padróes fixados pela mass midia, recusando, portanto, a fassion culture, e definir o papel do poder público na prestação de serviços culturais (como bibliotecas e escolas de arte) e no financiamento de produçóes culturais propostas pela sociedade.

Além da face negativa ou crítica, nossas propostas possuíam uma face positiva: a cultura foi pensada como direito dos cidadãos e a política cultural como cidadania cultural. Em outras palavras, procuramos marcar, desde o início, que a política cultural visava também a uma cultura política nova.

Que direitos procurávamos afirmar?

- Direito de acesso e de fruição dos bens culturais por meio dos serviços públicos de cultura (bibliotecas, arquivos históricos, escolas de arte, cursos, oficinas, seminários, gratuidade dos espetáculos teatrais e cinematográficos, gratuidade das exposiçóes de artes plásticas, publicação de livros e revistas etc.), enfatizando o direito à informação, sem a qual não há vida democrática;

- Direito à criaçáo cultural, entendendo a cultura como trabalho da sensibilidade e da imaginação na criação das obras de arte e como trabalho da inteligência e da reflexão na criação das obras de pensamento; como trabalho da memória individual e social na criação de temporalidades diferenciadas nas quais indivíduos, grupos e classes sociais possam reconhecer-se como sujeitos de sua própria história e, portanto, como sujeitos culturais.

- Direito a reconhecer-se como sujeito cultural, graças à ampliação do sentido da cultura, criando para isso espaços informais de encontro para discussóes, troca de experiências, apropriação de conhecimentos artísticos e técnicos para assegurar a autonomia dos sujeitos culturais, exposiçáo de trabalhos ligados aos movimentos sociais e populares. 
- Direito à participação nas decisões públicas sobre a cultura, por meio de conselhos e fóruns deliberativos nos quais as associaçōes artísticas e intelectuais, os grupos criadores de cultura e os movimentos sociais, através de representantes eleitos, pudessem garantir uma política cultural distanciada dos padröes do clientelismo e da tutela.

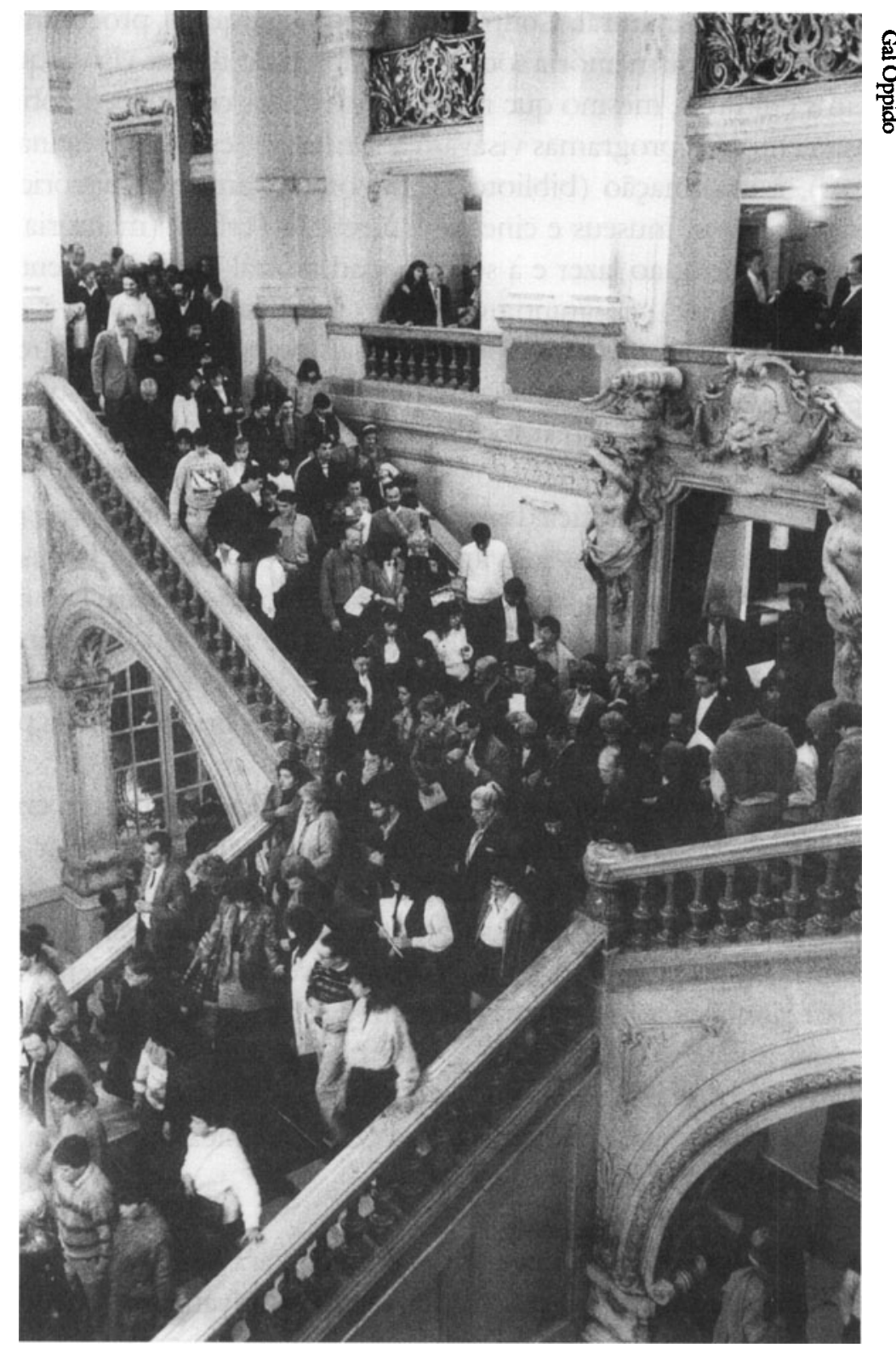

O Teatro Municipal de São Paulo, fundado em 12 de setembro de 1911, foi aberto à população "enfatizando o caráter píblico da agẫo cultural do Estado"

O projeto cultural colocou-se, portanto, na perspectiva da democratização da cultura como direito à fruição, à experimentação, à informação, à memória e à 
participação. Contra a violência visível e invisível dissimuladas pela mitologia da não-violência, demos prioridade a programas de compreensão crítica da sociedade e da história brasileiras. Contra o universo da mass midia, demos ênfase ao caráter expressivo, experimental e diversificado da criação cultural como trabalho. Contra o populismo, procuramos expandir a rede de serviços culturais que garantisse às camadas populares o acesso à informação e às formas mais avançadas da produção cultural. Contra o elitismo oligárquico, procuramos desenvolver não só projetos de memória social, mas sobretudo tornar visível que somos todos sujeitos culturais, mesmo que não sejamos todos criadores de obras de arte e de pensamento. Os programas visavam à formação (escolas e oficinas, seminários e cursos), à informação (bibliotecas, discotecas, arquivos históricos, videotecas, acesso a teatros, museus e cinemas), à reflexão crítica (memória oral, memória social e política), ao lazer e à solidariedade social (grandes eventos de música $\mathrm{e}$ dança ao ar livre), à garantia de acesso aos bens culturais e à criação cultural (ampliação e extensão para a periferia mais pobre da cidade da rede de bibliotecas, videotecas, discotecas, escolas de arte, teatros, centros culturais e casas de cultura, museus e casas históricas).

Recusamos a prática da animação cultural, substituindo-a pela ação cultural das comunidades, dos movimentos sociais e populares. Recusamos a celebraf̧ão oficial, substituindo-a pela comemoração sócio-política, isto é, pela memória social como elemento crítico do presente e do passado da sociedade brasileira. Recusamos o clientelismo, graças à discussão pública (em conselhos $\mathrm{e}$ fóruns de cultura) dos orçamentos públicos de cultura e das prioridades da política cultural.

A cidadania cultural teve em seu centro a desmontagem crítica da mitologia e da ideologia: tomar a cultura como um direito foi criar condiçôes para tornar visível a diferença entre carência, privilégio e direito, a dissimulação das formas da violência, a manipulação efetuada pela mass midia e o paternalismo populista; foi a possibilidade de tornar visível um novo sujeito social e político que se reconheça como sujeito cultural. Mas foi, sobretudo, a tentativa para romper com a passividade perante a cultura - $o$ consumo de bens culturais - e a resignação ao estabelecido, pois essa passividade e essa resignação bloqueiam a busca da democracia, alimentam a visão messiânica-mineralista da política e o poderio das oligarquias brasileiras.

Em suma, fizemos um esforço político para desenraizar as fundas raízes do mito fundador. Alguns dizem, pejorativa ou positivamente, que fomos... radicais.

Marilena Chaui é professora do Departamento de Filosofia da Faculdade de Filosofia, Letras e Ciências Humanas da USP.

Conferência do mês do IEA-USP feita pela autora em 6 de dezembro de 1994. 